\title{
Micoplasmose hemotrópica felina em onça-pintada (Panthera onca): relato de caso
}

\author{
Rafaela Guimarães Sanchioli \\ Rua Capitão Cirilo, 431, Alto Alegre, CEP 37795-000, Andradas - MG, Brasil \\ rgsanchioli@outlook.com
}

Submetido em 23/09/2014

Aceito para publicação em 13/02/2015

\section{Resumo}

Por estarem frequentemente sujeitos a situações estressantes, animais mantidos em cativeiro estão mais predispostos à imunossupressão. Quando na presença de infecções concomitantes ou em situações de estresse, Mycoplasma haemofelis pode desenvolver os sinais clínicos da micoplasmose hemotrópica felina. A transmissão do $M$. haemofelis ocorre por meio de vetores artrópodes hematófagos, como pulgas, carrapatos e piolhos. As infecções variam de anemia hemolítica com risco de morte iminente a anemia crônica sutil. A administração de imidocarb no tratamento de felinos selvagens infectados por hemoplasmas pode apresentar maior eficácia devido à sua natureza injetável e menor número de aplicações, quando comparado ao uso de doxiciclina por via oral durante um período maior. Como medida profilática para felinos selvagens, o enriquecimento ambiental aparenta ser mais eficaz quando comparado às demais formas de prevenção comumente adotadas em gatos domésticos. Este artigo tem por objetivo relatar um caso de micoplasmose hemotrópica felina em onça-pintada (Panthera onca) e discorrer sobre sua relação com a imunodepressão causada por condições de estresse em cativeiro.

Palavras-chave: Estresse; Imunossupressão; Mycoplasma haemofelis; Onça-pintada

\section{Abstract}

Feline hemotropic mycoplasmosis in jaguar (Panthera onca): case report. Being often subject to stressful situations, animals kept in captivity are more susceptible to immunosuppression. When in the presence of concurrent infections or under situations of stress, Mycoplasma haemofelis may develop the clinical symptoms of feline hemotropic mycoplasmosis. The transmission of M. haemofelis occurs through hematophagous arthropod vectors, such as fleas, ticks, and lice. Infections range from hemolytic anemia with risk of imminent death to subtle chronic anemia. Administration of imidocarb to treat wild felines infected with hemoplasms may show greater effectiveness due to its injectable nature and smaller number of applications when compared to the use of doxycycline orally for a longer period. As a prophylactic measure for wild cats, environmental enrichment seems to be more effective when compared to other prevention ways usually adopted in domestic cats. This article aims to report a case of feline hemotropic mycoplasmosis in jaguar (Panthera onca) and address its relation to the immunosuppression caused by stress conditions in captivity.

Key words: Immunosuppression; Jaguar; Mycoplasma haemofelis; Stress 


\section{Introdução}

A prática de manter animais em cativeiro é comumente relatada, embora estudos voltados às condições destes no ambiente cativo ainda sejam recentes (HASHIMOTO, 2008). Sabe-se que a sanidade do animal neste tipo de ambiente está relacionada tanto aos cuidados com sua integridade física quanto psicológica, onde se nota a importância do fator estresse (YOUNG, 2003).

Dentre as doenças ligadas à imunossupressão, as hemoparasitoses, particularmente a micoplasmose hemotrópica felina, são de comum observação em felídeos. Estes animais poderiam representar um importante reservatório para hemoplasmas devido à sua exposição comum para os artrópodes hematófagos (WILLI et al., 2007).

As diversas espécies de felinos selvagens apresentam diferentes susceptibilidades para infecções por hemoplasmas, as quais apresentam associação com vários fatores como idade, sexo, o ambiente em que se encontram, doenças intercorrentes ou estado imunitário, ressaltando a importância deste último (WILLI et al., 2007; 2009).

Infecções por hemoplasmas em gatos domésticos são frequentemente relatadas, enquanto que são escassas as informações quanto às infecções em felinos selvagens. A parasitemia parece ser intermitente nestes animais (HAEFNER et al., 2003; WILLI et al., 2007). Um estudo recente relatou a infecção por Mycoplasma haemofelis em dois tigres (HAEFNER et al., 2003).

Micoplasmas hemotrópicos são clinicamente relevantes como agentes causadores de anemia hemolítica nos animais infectados. Alguns animais correm risco de morte enquanto que outros, no entanto, desenvolvem apenas sinais leves, sendo até assintomáticos (PITSKO, 2003).

O presente trabalho tem como objetivo relatar um caso de Micoplasmose hemotrópica felina em onçapintada (Panthera onca) e discorrer sobre sua relação com a imunodepressão causada por condições de estresse em cativeiro.

\section{Relato de caso}

Onça-pintada, com aproximadamente cinco anos de idade, proveniente do Parque Walter World da cidade de Poços de Caldas, MG apresentava perda de peso, apatia e letargia progressivas e insidiosas. $\mathrm{O}$ animal foi encaminhado ao Hospital Veterinário da PUC Minas Campus Poços de Caldas para realização de ultrassonografia abdominal, devido a suspeita de piometra. Para tanto, o animal foi sedado com uso de dardo anestésico com tiletamina e zolazepam $(9,6 \mathrm{~mL}$ de Zoletil ${ }^{\circledR}$ por via intramuscular) e transportado em veículo próprio do Parque Walter World.

O recinto no qual o animal era mantido não apresentava nenhum tipo de enriquecimento ambiental. Notou-se a infestação de pulgas e carrapatos no ambiente de cativeiro.

Ao atendimento, no exame clínico o animal apresentou mucosas pálidas, esplenomegalia acentuada, desidratação severa, lesão na extremidade da cauda, temperatura corporal de $41,3^{\circ} \mathrm{C}$ e peso de $48 \mathrm{~kg}$.

À ultrassonografia, confirmou-se aumento acentuado do baço, não se observando nenhuma outra alteração. Foram realizados testes para o vírus da imunodeficiência felina (FIV) e para leucemia felina vírus (FeLV). Ambos se apresentaram negativos.

Procedeu-se à colheita de sangue para realização de hemograma com pesquisa de hematozoários e bioquímica renal e hepática. As veias cefálicas dos membros torácicos direito e esquerdo foram utilizadas para a venipunção com uso de agulhas descartáveis (calibre 25x8) e seringas descartáveis $(10 \mathrm{~mL})$.

$\mathrm{O}$ animal apresentou anemia severa macrocítica hipocrômica com intensos sinais de policromasia e anisocitose. Azotemia marcante foi notada. Não foram observadas alterações de bioquímica hepática. A pesquisa de hematozoários foi positiva para micoplasmose hemotrópica felina.

Realizou-se fluidoterapia com ringer lactato de sódio e administrou-se imidocarb $(2 \mathrm{ml}$ por via subcutânea) e dexametasona (9 mL por via subcutânea).

$\mathrm{O}$ animal veio a óbito após $24 \mathrm{~h}$, sendo submetido à necropsia. Os achados de necropsia incluíram 
esplenomegalia, hepatomegalia, lipidose hepática e carcaça ictérica. Análise histopatológica de fragmentos do fígado revelou vacuolização de citoplasma dos hepatócitos, difusos e acentuados, necrose individual de hepatócitos e colestase biliar.

\section{Discussão}

A presença do micoplasma no esfregaço sanguíneo não necessariamente correlaciona-se à etiologia da anemia, mas na presença de outros sinais, como esplenomegalia, hepatomegalia e icterícia, e dos resultados de hemograma, como aumento absoluto no número de reticulócitos, levam a considerá-lo como agente causal.

Os dados clínicos são confirmados pela necropsia. Esplenomegalia e hepatomeliga se correlacionam à hematopoiese extramedular, que ocorre como um mecanismo fisiológico compensatório. A hepatomegalia é decorrente de lipidose hepática causada pela anorexia. A anemia pode ser resultante de dano eritrocítico direto ou pelo depósito de micoplasmas no baço, após a retirada dos agentes de hemácias infectadas (FILONI, 2006).

A insuficiência renal pode estar relacionada ou não à infecção por M. haemofelis, embora esta relação não esteja comprovada em relatos da micoplasmose. A disfunção renal decorrente da hemoparasitose pode ser causada pela hemólise, onde a hemoglobina causa destruição dos túbulos renais. A insuficiência renal pode, ainda, ser decorrente de nefropatia pré-existente, hipóxia renal ou pela redução do fluxo sanguíneo pela desidratação severa.

Mycoplasma haemofelis é um agente que raramente causa manifestações clínicas, mas pode causá-las em situações de estresse ou por meio de infecções concomitantes por agentes imunossupressores. Mycoplasma haemofelis poderá desenvolver os sinais clínicos da micoplasmose hemotrópica felina. A presença de ectoparasitas hematófagos, como carrapatos, pulgas e piolhos aumenta o risco de infecção.

Animais mantidos em cativeiro estão mais predispostos à infecções por agentes imunossupressores pelo fato de estarem frequentemente sujeitos à situações estressantes. A falta de estímulos próximos aos vivenciados pelo animal em vida livre provoca uma desestimulação deste no ambiente cativo e aparenta ser o principal fator estressante de animais em cativeiro. A lesão observada na extremidade da cauda corresponde ao provável comportamento estereotipado de automutilação causada por estresse.

Por meio de técnicas de enriquecimento ambiental, resultados fisiológicos e comportamentais favoráveis podem ser observados em animais cativos (YOUNG, 2003). O animal que apresentar condições de bem estar físico e psíquico estará fortemente disposto a combater possíveis agentes patogênicos.

Embora notificações de micoplasmose hemotrópica felina em animais selvagens sejam escassas, a infecção por $M$. haemofelis deve ser considerada.

A administração de imidocarb no tratamento de felinos selvagens infectados por hemoplasmas pode apresentar maior eficácia por sua natureza injetável e menor número de aplicações, quando comparado ao uso de doxiciclina por via oral durante um maior período de tempo.

Por apresentarem maior risco de imunossupressão decorrente de situações estressantes, além de estarem mais expostos aos vetores artrópodes hematófagos, tendo em vista o difícil controle de ectoparasitas nas espécies selvagens; os hemoplasmas podem desencadear uma infecção mais severa nestes animais.

Como medida profilática, o enriquecimento ambiental aparenta ser mais eficaz quando comparado às demais formas de prevenção comumente realizadas em gatos domésticos.

Além da sua contribuição para uma melhor qualidade de vida dos animais mantidos em cativeiro, o enriquecimento do ambiente cativo é capaz de prevenir a ocorrência de doenças diretamente ligadas à imunossupressão.

\section{Referências}

FILONI, C. Exposição de felídeos selvagens a agentes infecciosos selecionados. 2006. 128 f. Tese (Doutorado em Patologia Experimental e Comparada) - Universidade de São Paulo, São Paulo. 2006. 
HAEFNER, M.; BURKE, T. J.; KITCHELL, B. E.; LAMONT, L. A.; SCHAEFFER, D. J.; BEHR, M.; MESSICK, J. B. Identification of Haemobartonella felis (Mycoplasma haemofelis) in captive nondomestic cats. Journal of Zoo and Wildlife Medicine, Lawrence, v. 2, n. 34, p. 139-143, 2003.

HASHIMOTO, C. Y. Comportamento em cativeiro e teste da eficácia de técnicas de enriquecimento ambiental (físico e alimentar) para jaguatiricas (Leopardus pardalis). 2008. 141 f. Dissertação (Mestrado em Psicologia) - Universidade de São Paulo, São Paulo. 2008.

PITSKO, L. E. Wild tigers in captivity: a study of the effects of the captive environment on tiger behavior. 2003. $71 \mathrm{f}$. Dissertation (Master in Science) - Faculty of Virginia Polytechnic Institute and State University, Virgínia. 2003.
WILLI, B.; FILONI, C.; CATÃO-DIAS, J. L.; CATTORI, V.; MELI, M. L.; VARGAS, A.; MARTÍNEZ, F.; ROELKE, M. E.; RYSER-DEGIORGIS, M. P.; LEUTENEGGER, C. M.; LUTZ, H.; HOFMANN-LESHMANN, R. Worldwide occurrence of feline hemoplasma infections in wild felid species. Journal of Clinical Microbiology, Washington, v. 45, n. 4, p. 1159-1166, 2007.

WILLI, B.; MELI, M. L.; LUTHY, R.; HONEGGER, H.; WENGI, N.; HOELZLE, L. E.; REUSCH, C. E., LUTZ, H.; HOFMANNLEHMANN, R. Development and application of a universal hemoplasma screening assay based on the SYBR green PCR principle. Journal of Clinical Microbiology, Washington, v. 47, n. 12, p. 4049-4054, 2009.

YOUNG, R. J. Environmental enrichment for captive animals. Oxford: Blackwell Publishing, 2003. 228 p. 